\title{
Use of Direct Behavior Ratings as the Foundation of Tier 2 Service Delivery
}

\author{
Stephen P. Kilgus \\ East Carolina University
}

\begin{abstract}
With the advent of multi-tiered problem solving frameworks, including positive behavior interventions and supports (PBIS), has come increasing emphasis on general education classroom teachers serving as data collectors, assessors, and interventionists for students demonstrating problem behavior. As such, there is need for teachers to have access to strategies that can be used as a foundation of service delivery and that are appropriate in assessment, intervention, and communication across a wide range of students and situations. Research suggests that Direct Behavior Rating (DBR) is a particularly promising tool for tracking student progress, affecting change in student behavior, maintaining and generalizing treatment effects over time and settings, and enhancing communication between school professionals and families. This article offers an overview of DBR and its various uses and suggestions for practitioners in implementing it as a tool for Tier 2 support.
\end{abstract}

An overarching goal of positive behavior interventions and supports (PBIS) is to ensure the timely provision of preventative strategies that match student needs and support academic and social growth. Each of the three levels used in this multi-tiered problem solving framework represents a combination of systems and practices of service delivery for students demonstrating challenging behaviors (Simonsen, Sugai, \& Negron, 2008). Tier 2 is designed to assist students who have not adequately responded to universal strategies at Tier 1 , and whose behavior is considered disruptive to the instructional context, without being extremely serious or dangerous to self or others (Sanetti \& Simonsen, 2011).

To be considered for adoption by teachers, three prominent practices used in Tier 2 service delivery - assessment, intervention, and communication - should possess multiple characteristics (Chafouleas, Riley-Tillman, \& Christ, 2009). Assessment tools used for monitoring student behavior should be psychometrically defensible, usable, repeatable, and flexible (Chafouleas, Volpe, Gresham, \& Cook, 2010; Christ, Riley-Tillman, \& Chafouleas, 2009). Intervention tools used to increase positive behavior and reduce negative behavior should be empirically-based and affect immediate, maintainable, and generalizable change in student behavior (Kratochwill, 2007). Interventions should also be efficient, applicable to a range of students, functionbased, and implemented with integrity (Campbell \& Anderson, 2011; Hawken, Adolphson, Macleod, \& Schumann, 2009; McIntosh, Brown, \& Borgmeier, 2008; Sanetti 
\& Kratochwill, 2009). Communication tools used to share student progress should be frequent, immediate, continuous, and substantive if they are to facilitate the coordination of services across settings, foster stakeholder buy-in and participation, and promote stakeholder accountability for intervention integrity and success (Hauerwas \& Goessling, 2008). These tools should facilitate home-school collaboration promoted within legislation and by professional organizations (e.g., Title I of the Elementary and Secondary Education Act in 1965; Division 16 of the American Psychological Association, National Association of School Psychologists). See Table 1 for a review of the characteristics defining each of these Tier 2 practices.

Table 1

Tier 2 tools and associated characteristics

\begin{tabular}{|c|c|}
\hline Tools and Characteristics & Definition \\
\hline \multicolumn{2}{|l|}{ Assessment } \\
\hline Defensible & Sufficiently valid, reliable, and sensitive to change \\
\hline Usable & Efficient, acceptable to stakeholders, and cost effective \\
\hline Repeatable & $\begin{array}{l}\text { Suitable for formative use across time and settings to yield a } \\
\text { data stream }\end{array}$ \\
\hline Flexible & $\begin{array}{l}\text { Capable for use across a range of students, settings, and } \\
\text { target behaviors }\end{array}$ \\
\hline \multicolumn{2}{|r|}{ 7. } \\
\hline Evidence-based & $\begin{array}{l}\text { Ability to affect rapid, maintainable, and generalizable } \\
\text { behavior change based on empirical research }\end{array}$ \\
\hline Efficient & $\begin{array}{l}\text { Feasibility, cost effectiveness, and potential for rapid } \\
\text { application with little disruption to the instructional ecology }\end{array}$ \\
\hline General & $\begin{array}{l}\text { Defensible for use across multiple students, settings, and } \\
\text { outcome variables with minimal adaptation }\end{array}$ \\
\hline Function-based & $\begin{array}{l}\text { Hypothesized function of problem behavior targeted via } \\
\text { manipulation of the environmental contingencies known to } \\
\text { promote growth and inhibit problem development }\end{array}$ \\
\hline Treatment integrity & $\begin{array}{l}\text { Implemented as intended and in accordance with evidence- } \\
\text { based procedures }\end{array}$ \\
\hline \multicolumn{2}{|l|}{ Communication } \\
\hline Frequent & Shared between stakeholders on daily or weekly basis \\
\hline Continuous & $\begin{array}{l}\text { Maintained over a period of time and corresponding to } \\
\text { specific times or intervention phases (e.g., baseline, } \\
\text { intervention, maintenance) }\end{array}$ \\
\hline Substantive & $\begin{array}{l}\text { Detailed quantitative or qualitative feedback sufficiently } \\
\text { characterizes student status and progress }\end{array}$ \\
\hline Efficient & Little time and effort required \\
\hline
\end{tabular}

Note: Practices and corresponding definitions adapted from Campbell \& Anderson (2011), Chafouleas et al. (2002), Hawken et al. (2009), Kratochwill (2007), McIntosh et al. (2008), and Sanetti \& Kratochwill (2009). 
A review of the literature reveals that many different tools and procedures may be used as part of assessment (e.g., systematic direct observation), intervention (e.g., social skills instruction), and communication (e.g., narrative home-school notes) at Tier 2. Schools may adopt a series of these single purpose tools and procedures in carrying out each of the three Tier 2 practices; however, the time and resources associated with adoption, training, and sustained implementation of multiple tools may prove costly. Although each may be efficient in its individual role, the need to apply multiple tools may lessen the utility of the broader service delivery process. It would therefore be preferable to adopt a single multi-purpose tool with utility in all three practices. Research suggests that such a tool might be found in Direct Behavior Rating (DBR; Christ, Riley-Tillman, \& Chafouleas, 2009). DBR's high utility and wide applicability positions it for use as the foundation of Tier 2 services for most students who need this level of support (Chafouleas, 2011). Although it may not be sufficient for every student, the flexibility, effectiveness, and efficiency of DBR indicates that it may be a highly useful component. The purpose of this article, therefore, is to provide an overview of DBR and describe how it may be used as a tool for assessment, intervention, and communication during Tier 2 service delivery.

\section{Direct Behavior Rating}

Direct Behavior Rating (DBR) has been described as an umbrella term subsuming multiple tools that employ similar design and procedures (Chafouleas, 2011). Several characteristics and procedures connect these tools and define each as part of the DBR category (Chafouleas, Riley-Tillman, \& McDougal, 2002; Vannest, Davis, Davis, Mason, \& Burke, 2010).

First, DBR includes one or more pre-specified behaviors that are rated by an individual with whom the student comes into frequent contact, most often a classroom teacher. Behaviors are either narrowly defined to represent specific and relatively discrete behaviors, or broadly defined to represent multiple narrow behaviors. See Table 2 for examples of both narrow and broad behaviors. Second, the DBR user (e.g., teacher) completes a rating by assessing a target behavior one or more times per day. Each rating corresponds to the behavior displayed by the student within a pre-specified period and location. The length and nature of rating periods may vary (e.g., 3- or 4-hour half days, 45-60-minute academic activities, 10-minute within-activity segments; Chafouleas et al., 2010; Chafouleas, Sanetti, Kilgus, \& Maggin, 2012; Kilgus, Chafouleas, Riley-Tillman, \& Welsh, 2012). Ratings are completed at the end of each time period in an attempt to facilitate accuracy and limit bias that may be introduced following lags between observation and recording. Third, collected DBR data are communicated across multiple stakeholders either within classrooms or other settings (.e.g., playground, cafeteria) or between school and home. This information transmission is intended to facilitate collaboration among teachers and parents and should occur on a regular and systematic basis. 
Table 2

Examples of narrowly and broadly defined behaviors for Direct Behavior Rating

\begin{tabular}{ll}
\hline Broadly Defined Behaviors & Corresponding Narrowly Defined Behaviors \\
\hline Academic engagement & $\begin{array}{l}\text { Raising hand } \\
\text { Writing } \\
\text { Talking about a lesson }\end{array}$ \\
& $\begin{array}{l}\text { Out of seat } \\
\text { Fidgeting } \\
\text { Calling out }\end{array}$ \\
& Following teacher directions \\
Respect & Pro-social interaction with peers \\
& Positive response to adult request \\
Aggression & Kicking \\
& Throwing of objects \\
& Yelling at others \\
\hline
\end{tabular}

Note: Behaviors adapted from Chafouleas et al. (2007), Chafouleas et al. (in press), RileyTillman, Chafouleas, Christ, Briesch, \& LeBel (2009).

\section{Single-Item Scales and Multi-Item Scales}

There are two broad categories of DBR: Single-Item Scales (DBR-SIS) and MultiItem Scales (DBR-MIS; Christ et al., 2009). Ratings collected via DBR-SIS are interpreted within each individual item. That is, if a DBR-SIS user rated a student across three target behaviors, interpretation would include consideration of the extent of each individual behavior within a rating period, rather than all three behaviors combined. Single items typically correspond to broadly defined behaviors (see Table 2). Ratings are recorded on a unipolar graphic rating scale divided into 10 equal segments, each of which corresponds to a number 0-10. Ratings are quantitative, representing user perception of the extent of the behavior during a rating period, such as its duration, frequency, or percentage. See Figure 1 for an example of a standard DBR-SIS form used to rate three broadly defined behaviors of academically engaged behavior, respectful behavior, and disruptive behavior. 
Direct Behavior Rating (DBR) Form: 3 Standard Behaviors

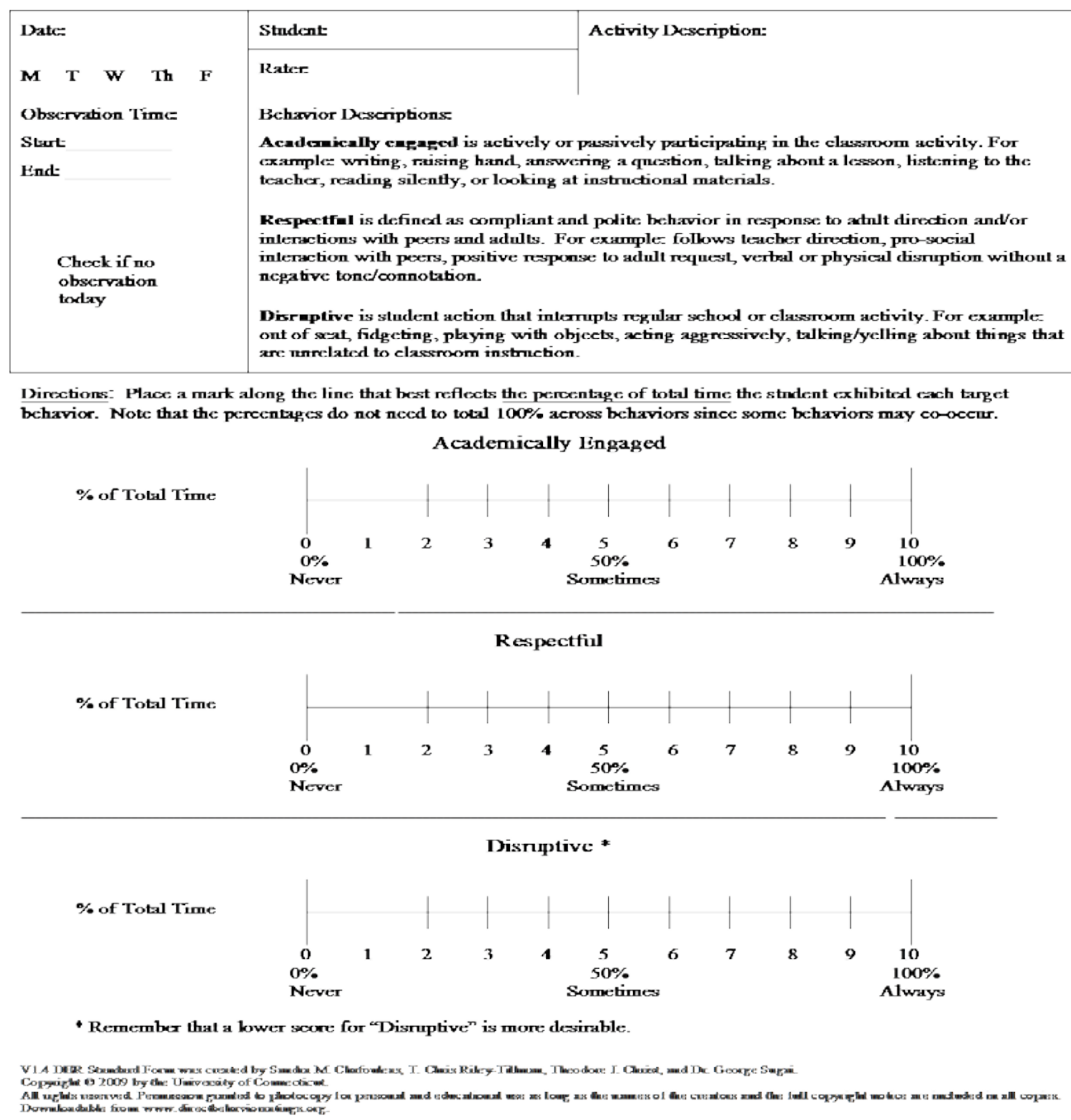

Figure 1. Direct Behavior Rating Single-Item Scale Form (www.directbehaviorratings.org).

In contrast to DBR-SIS, interpretation of Multi-Item Scales (DBR-MIS) calls for consideration of a single aggregate score, such as a summed or mean score, that summarizes all behaviors considered within a rating period. In previous research, the items comprising DBR-MIS frequently corresponded to narrow and specific behaviors, such as on-task behavior (playing appropriately with others,) and activity change (moving from one center to another; McCain \& Kelley, 1993). More recent studies have considered the use of DBR-MIS with schoolwide behavioral expectations and Individualized Education Program (IEP) goals and objectives (Burke, Vannest, Davis, Davis, \& Parker, 2009; Crone, Hawken, \& Horner, 2010; Fabiano, Vujnovic, Naylor, Pariseau, \& Robins, 2009; Fabiano et al., 2010). 
Direct Behavior Rating - Multi-Item Scale

\begin{tabular}{|l|rrr|rrr|rrr|r|r|r|}
\hline & \multicolumn{2}{|c|}{ Raised Hand } & \multicolumn{2}{|c|}{ Hands to Self } & \multicolumn{2}{|c|}{ Stayed in Seat } & Total Points \\
\hline Math & 0 & 1 & 2 & 0 & 1 & 2 & 0 & 1 & 2 & \\
\hline Science & 0 & 1 & 2 & 0 & 1 & 2 & 0 & 1 & 2 & \\
\hline Social Studies & 0 & 1 & 2 & 0 & 1 & 2 & 0 & 1 & 2 & \\
\hline Language Arts & 0 & 1 & 2 & 0 & 1 & 2 & 0 & 1 & 2 & \\
\hline Art & 0 & 1 & 2 & 0 & 1 & 2 & 0 & 1 & 2 & \\
\hline Total & & & & & & & & & & \\
\hline
\end{tabular}

Please rate the extent to which the student engaged in each of the following three behaviors during each of the five academic activities:

$$
0=\text { Never, } 1 \text { = Sometimes, } 2 \text { = Often }
$$

1. Raised Hand - Student raised hand and waited to be called on by the teacher prior to communicating verbally to his peers or teachers.

2. Hands to Self - Student did not make physical contact with others unless shaking hands, giving a high five, or if it was a necessary part of an academic task.

3. Stayed in Seat - Student sat in his seat during all activities unless given permission to leave his seat by an adult.

\begin{tabular}{|c|c|c|c|}
\hline Total score = & & & \\
\hline Goal score = & & & \\
\hline Reward level = & 1 & 2 & 3 \\
\hline Reward chosen = & & & \\
\hline $\begin{array}{l}\text { Time reward was } \\
\text { provided = }\end{array}$ & & & \\
\hline
\end{tabular}

Figure 2. Example Direct Behavior Rating Multi-Item Scale Form.

DBR-MIS ratings can be quantitative, representing an estimate of the extent of the behavior during a rating period, or qualitative, indicating estimates of how well a student completed his or her assignment (Jurbergs, Palcic, \& Kelley, 2007; Vannest et al., 2010). Ratings are typically completed using Likert-type scales, with either numerical (e.g., $1=$ Tough time, $2=\mathrm{OK}, 3=$ Good, $4=$ Perfect) or graphical categories (e.g., $:)=$ consistent, $:-$ = somewhat consistent, $: ;=$ inconsistent; LeBel, Chafouleas, 
Britner, \& Simonsen, 2013; Stage, Cheney, Lynass, Mielenz, \& Flower, 2012). See Figure 2 for an example DBR-MIS form including three narrow target behaviors, raised hand, hands to self, and stayed in seat.

\section{Direct Behavior Rating as Tier 2 Assessment Tool}

Through a national survey of teachers, Chafouleas, Riley-Tillman, and Sassu (2006) examined the purpose for which DBR had been used in school settings. The majority of teachers (64\%) reported use of the tool for intervention purposes. In addition, nearly one-third of respondents (32\%) indicated they had also used DBR in assessment, despite the absence of evidence for its use in this capacity. Recognition of teacher interest in this application of DBR drove research examining DBR utility in assessment. An extensive series of studies have established DBR-SIS as a viable assessment tool. Initial research resulted in recommendations for DBR-SIS data collection procedures and target behaviors (Chafouleas, Christ, \& Riley-Tillman, 2009; Riley-Tillman, Chafouleas, Christ, Briesch, \& LeBel, 2009; Riley-Tillman, Christ, Chafouleas, Boice, \& Briesch, 2010). Subsequent studies yielded suggestions for DBRSIS scale design, with results indicative of the optimal number of scale gradients (5 vs. 10-point scale) and length of scale (50 vs. 100mm; Briesch, Kilgus, Chafouleas, RileyTillman, \& Christ, 2012). Recent studies have supported the use of DBR-SIS in progress monitoring, demonstrating the tool's utility in tracking change in student behavior across baseline and intervention conditions (Chafouleas et al., 2010). Findings have been indicative of the measure's concurrent validity, sensitivity to change, and generalizability and dependability (Chafouleas et al., 2010; Chafouleas, Riley-Tillman, Sassu, LaFrance, \& Patwa, 2007; Chafouleas, Sanetti, Kilgus, \& Maggin, 2012; RileyTillman, Chafouleas, Briesch, \& Eckert, 2008). Together this research supports the use of DBR-SIS for assessment in making decisions, such as those used at Tier 2 regarding student responsiveness to intervention.

When DBR is used for progress monitoring purposes, a decision must first be made as to whether the DBR will be a single-item scale (SIS) or multi-item scale (MIS). Next, educators must select and define the target behaviors that will be rated. Within the DBR-SIS realm, there is an extensive research base measuring target behaviors of disruptive behavior, academic engaged behavior, and respectful behavior (Chafouleas, Riley-Tillman \& Christ, 2009). Each has been considered a general outcome measure, and indicative of student likelihood for social and academic success in school settings (Chafouleas, 2011). Educators must specify the times and locations within which DBR data will be collected. They must also decide how frequently DBR data will be collected (e.g., once a week, once a day, multiple times per day). DBR data collection is analogous to systematic direct observation data collection, with each DBR data point regarded as a sample of the student's behavior within a specific time (e.g., Tuesday 10:00-10:45am) and space (e.g., large group math instruction in the general education setting). DBR data may also be interpreted in a manner consistent with single-case 
research, in that it can be collected across design phases (e.g., Baseline, Intervention 1, Intervention 2), graphed, and visually analyzed in evaluating student response to intervention (Chafouleas, 2011; Christ et al., 2009). See Figure 3 for an example of how DBR Multi-Item Scale data might be graphed to track a student's progress across multiple baseline and intervention phases of implementation.

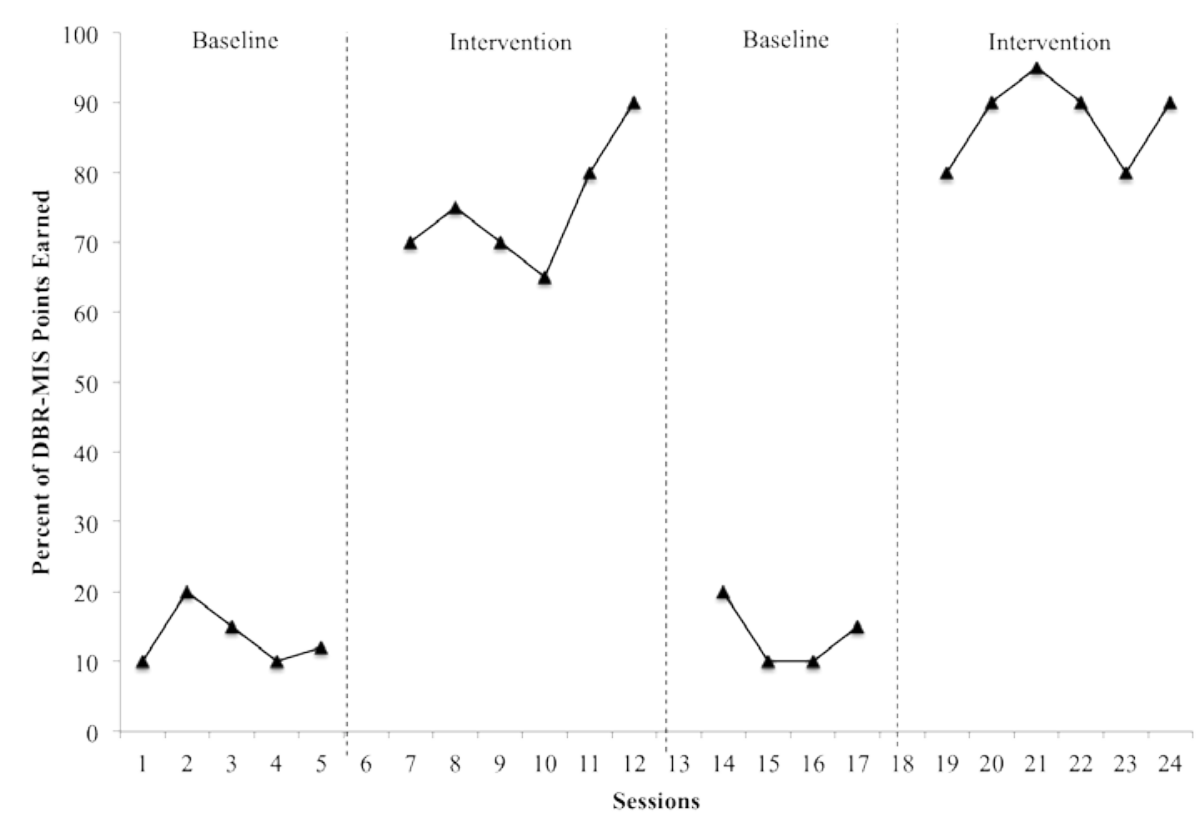

Figure 3. Example graph of Direct Behavior Ratings Multi-Item Scale data.

\section{Direct Behavior Rating as Tier 2 Intervention Tool}

Whether a DBR will be used in Tier 2 as an intervention tool is determined by how and with whom educators decide to share data. The decision to share information with a target student allows DBR data to serve as the basis of performance feedback to the student regarding his or her behavior. This feedback alone may serve as an intervention with the potential to positively affect student performance (Jurbergs et al., 2010). In situations where feedback might be insufficient, DBR assessment data may be tied to further behavioral interventions and supports to enhance the likelihood of intended outcomes. For instance, DBR ratings can be used to determine whether student behavior should be reinforced (Vannest et al., 2010). Educators could specify that students will receive a reward if their performance, as indicated by DBR ratings, exceeds some pre-specified criterion. Such criteria might include a rating of less than ' 2 ' on a DBR-SIS for disruptive behavior, or the receipt of at least 3 of 4 check marks across the school day on a DBR-MIS indicative of compliance with school rules. Rewards can be primary reinforcers, such as preferred activities or items, or secondary reinforcers, such as tokens, which may be accumulated over time and exchanged for primary reinforcers (Crone et al., 2010; Jurbergs et al., 2010). Although primarily 
considered a positive approach focused on the reinforcement of appropriate behavior, research has also established precedence for the use of DBR data in determining whether student behavior should be punished, with students losing access to reinforcing stimuli if their performance does not meet a pre-specified criterion (Jurbergs, Palcic, \& Kelley, 2007).

Whether provided or removed, care should be taken to ensure that stimuli are aligned with the function of the student's behavior, as an extensive line of research indicates the effectiveness of function-based interventions outweighs that of nonfunction-based alternatives (Filter \& Horner, 2009; Ingram, Palmer, \& Sugai, 2005). Such alignment may be assisted by functional behavior assessments (FBA) and reinforcer preference assessments. The former may be used to identify the function of a student's behavior, whereas the latter suggests which specific stimulus within the functional category the student will prefer. For instance, a FBA might indicate that a student's problem behavior functions to attain him or her access to tangibles and activities. A subsequent preference assessment might suggest that particularly reinforcing items and activities include toys, stickers, and board games. Although neither assessment is typically considered a component of Tier 2 services, increasing evidence supports use of such assessments if these services can be reasonably expected to affect student behavior (McIntosh et al., 2008).

DBR intervention effectiveness was recently evaluated via a meta-analysis of the DBR single-case research literature. Vannest et al. (2010) evaluated 17 studies yielding 48 unique effect sizes. Variance in DBR effectiveness was noted, but a mean improvement rate different (IRD) effect size of 0.61 was indicative of small to moderate effectiveness. Variables found to moderate DBR effectiveness included parental involvement, duration of daily implementation, and scale construction. That is, results indicated that DBR was more efficacious if (a) parents were involved in implementation, (b) it was implemented for more than one hour of each school day, and (c) teacher DBR ratings were either qualitative or both qualitative and quantitative. Other variables, including student grade and target behavior, were not found to moderate DBR effectiveness. In general, findings suggested DBR is likely to be effective under most circumstances and with most individuals. Specifically, research indicates that DBR effectiveness is consistent across students displaying various target behaviors, including on-task behavior, disruptive behavior, and various clinical symptoms (McCain \& Kelley, 1993; Pelham et al., 2002). Evidence also supports its use to address problem behaviors displayed for a range of functions, including gaining adult attention, peer attention, and access to preferred items and activities (Campbell \& Anderson, 2008, 2011; LeBel et al., 2013). DBR has also been found to support students of various backgrounds, including elementary students, secondary students, students of minority ethnicity, and students with psychiatric diagnoses (Fabiano et al., 2010; Gable, 2002; Jurbergs et al., 2010; Owens et al., 2012; Power et al., 2012; Williams et al., 2012). 


\section{Generalization and Maintenance}

The majority of DBR intervention research has considered the effectiveness of the tool when completed by an adult, including parents and teachers. Yet, requiring students to independently or collaboratively complete DBR ratings as part of a selfmanagement procedure holds multiple potential benefits (Briesch \& Chafouleas, 2009). For example, it is likely that self-management will conserve teacher time and effort, which may then be rededicated to other responsibilities. It is also likely to foster student independence and increase the likelihood of expected behavior being displayed without adult contingency manipulation. This phenomenon may be characterized in two ways. First, DBR-based self-management may bolster generalization of intervention effects. That is, it may increase the chance of expected behaviors being displayed under conditions other than those in which a specific intervention took place (Abikoff et al., 2004; Brooks, Todd, Tofflemoyer, \& Horner, 2003). Second, DBR-based selfmanagement may support intervention maintenance, or the preservation of treatment effects over time within the treatment setting (Webber, Scheuermann, McCall, \& Coleman, 1993). The importance of these findings should not be understated, as generalization and maintenance are highly desired outcomes that are required of any intervention if it is to be considered "truly" effective (Baer, Wolf, \& Risley, 1968). Given their frequently elusive nature, it is commonly accepted that specific programming is necessary to bring about both outcomes. That some evidence exists supporting the incorporation of DBR into such programming is particularly promising and should encourage the inclusion of the procedure into the teacher intervention repertoire.

\section{Treatment Integrity}

However DBR is to be used, whether it is completed by teachers or students, used as the basis of feedback or positive reinforcement, or used to treat general classroom behavior or symptoms tied to psychiatric diagnoses, it is necessary that DBR be implemented with integrity. Treatment integrity, or the application of treatments in accordance with empirically derived procedures, has been defined as a necessary condition of evidence-based practice in school settings (Kratochwill et al., 2012). It is considered a prerequisite of internally valid decision-making regarding student response to intervention and is thought to increase the likelihood of intervention effectiveness (Gresham, 1989). Those engaging in educational practice founded in science should both document the integrity with which interventions have been implemented and intervene for the purpose of improving integrity when it is found to be lacking (Sanetti \& Kratochwill, 2009). See below for information regarding how the communication of DBR may be used as the basis of a treatment integrity intervention.

\section{Direct Behavior Rating as Tier 2 Communication Tool}


Research supporting consideration of DBR data as indicative of student behavior in school settings has established its utility as a communication tool. By yielding technically adequate assessment data, DBR may be used as the foundation of substantive communication between various stakeholders regarding student progress and intervention success (Christ et al., 2009).

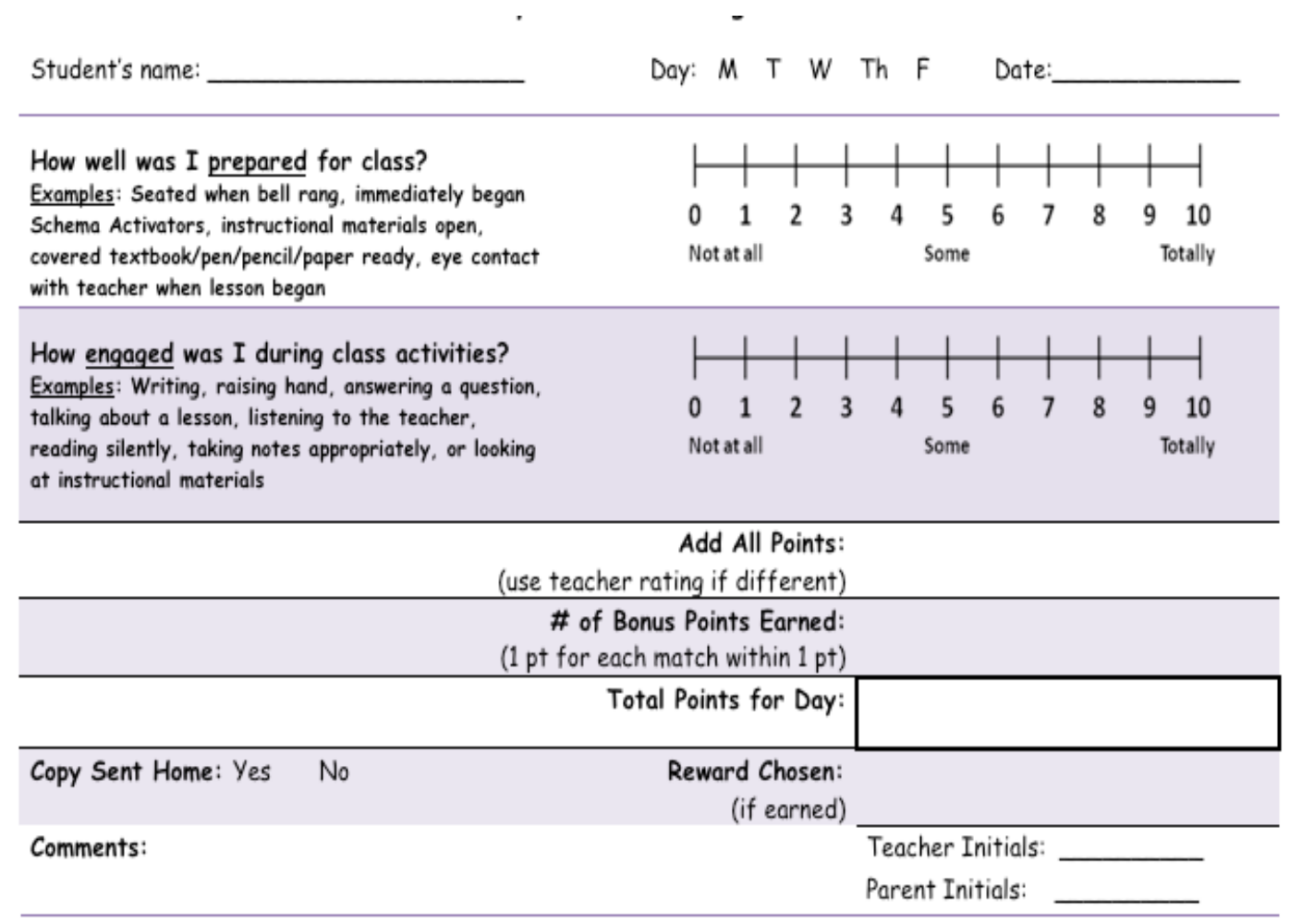

Figure 4. Student self-reported school-home note (www.directbehaviorratings.org).

School-home communication provides several potential benefits. First, the efficiency of DBR and its potential to be used on a consistent and repeated basis is likely to facilitate the frequent transmission of information known to support positive student behavior (Solomon, Klein, \& Politylo, 2012). Feedback regarding student progress may assist stakeholders in making informed, timely, and collaborative decisions, thus enhancing the potential for coordination of appropriate and evidencebased supports. Second, correspondence between teachers and parents may enhance stakeholder accountability for positive student outcomes (Frafjord-Jacobson, Hanson, McLaughlin, Stansell, \& Howard, 2013). Communication between stakeholders regarding student progress may help create a shared sense of concern for student behavioral improvement, as parents and educators share data indicative of the extent of the student's problem behavior. This understanding of the state of affairs may enhance stakeholder perception of responsibility for the development of an effective intervention plan and for ensuring that it is implemented with integrity. 
Third, communication may increase the responsiveness of school psychologists, counselors, and other support staff to teacher needs, as DBR progress monitoring data may indicate the necessity of additional resources or support in the classroom. This may in turn lead to educator perceptions of support for their work, resulting in reaffirmed commitment to the plan and attainment of goals. Fourth, communication between home and school settings regarding student engagement and achievement holds the potential to increase parental involvement (Thames, Pang, \& Watkins, 2000). Research supports the crucial nature of parental interest and participation in the educational process, as it has been found to be beneficial for students, parents, and teachers to influence emotional, behavioral, and academic outcomes, and more specifically, to increase the effectiveness of DBR as an intervention (Epstein, 1995; Vannest et al., 2010; Walberg, 1984).

\section{Communicating with Treatment Integrity Data}

Alternative forms of DBR-based data have also been found to be useful in the communication process. For instance, researchers have considered completed DBR forms as permanent products indicative of the integrity with which teachers have implemented interventions in the classroom. To evaluate teacher treatment integrity, one should examine permanent product recordings made on the DBR form as part of the normal intervention routine to determine whether each step was implemented as intended (Lane et al., 2004). These steps include the completion and summation of ratings, the provision of praise and feedback, the comparison of observed performance to goal performance, and the administration of rewards. This information may then be communicated to the teacher as part of performance feedback intended to influence their behavior as it pertains to intervention implementation. Witt, Noell, LaFleur, and Mortensen (1997) provided teachers daily feedback in the form of graphs representing student performance and percentage of treatment steps completed. Feedback also specified missed treatments steps and recommendations for addressing them. Results of the multiple baseline single case design indicated large increases in the level of treatment integrity in response to performance feedback, with the majority of teachers demonstrating consistently high levels of fidelity that were maintained over time. Results of a meta-analysis by Solomon, Klein, and Politylo (2012) suggested that such feedback is likely to have moderate effects on the integrity with which teachers implement school-based behavioral interventions. Findings further suggested that effects were consistent across grade levels and educational settings (i.e., general and special education), and that feedback was more effective when delivered within at least one day of performance.

Additional forms of DBR-based treatment integrity assessment tools have been proposed. For instance, it has been suggested that teachers might use DBR-SIS to self-rate less frequently considered dimensions of treatment integrity such as enthusiasm (Sanetti, Chafouleas, Christ, \& Gritter, 2009). This information, when 
considered along with other fidelity data (e.g., DBR permanent products) may generate a richer characterization of treatment integrity. When communicated to teachers, it is hoped that this enhanced data will lead to more detailed performance feedback, resulting in improved treatment integrity and student outcomes.

\section{Direct Behavior Rating as Integrated System of Support}

In summary, use of one instrument, DBR, may ultimately enhance the efficiency and sustainability of Tier 2 service delivery, as three essential Tier 2 practices can be carried out using this single tool. Yet, it is not enough that educators adopt an evidencebased tool to support students identified for Tier 2 services. To fulfill its intended purpose, whether it is to monitor a student's progress, change his or her behavior, or communicate about him or her to multiple stakeholders, it is necessary that the tool be applied in accordance with evidence-based procedures (Gresham, 1989). That is, how teachers apply DBR should closely approximate how researchers employed the tool within the investigations through which evidence has been gathered. Furthermore, DBR procedures should be as simple and efficient as possible, as procedures that do not substantially disrupt the normal classroom routine are more likely to be adopted and used over time with integrity. It is therefore suggested that teachers work with a student support team, including school psychologists and other support staff, to devise DBR procedures that are sustainable, acceptable, and effective. Both a review of the literature and applied experience suggest each of the following procedural recommendations should be considered during this team-based planning process.

Whether DBR is to be used for assessment, intervention, communication, or some combination thereof, it is advisable to begin by targeting a small number (e.g., 13) of important broad or narrow behaviors. Each of these behaviors should be rated only 1-2 times per day at the outset. The specific times and settings within which behaviors are rated should be those found to be most problematic for the target student, and therefore most deserving of attention. By starting with a small number of behaviors and daily ratings, teachers will have an opportunity to become fluent with DBR procedures, and more fully integrate the tool into the daily routine. Once fluency is reached and DBR procedures have been sufficiently integrated, the support team should work to increase the number of target behaviors and locations/times within which data are collected. This process should continue until DBR has addressed all behaviors and settings that are of concern for that student.

Beyond simple and efficient, DBR procedures must also be designed to promote the likelihood that the tool's use will yield intended outcomes. Which design recommendations should be incorporated is dependent upon the practice within which DBR will be applied. When used for assessment purposes, the support team should work in advance to establish a specific plan regarding how DBR data will be interpreted and used. 
Despite good intentions, teachers may hesitate to adopt DBR as progress monitoring tools if they do not believe collected data will actually be used to inform student-related decisions. These teachers could not be blamed for this reticence, as their anticipations are unfortunately often realized. It is therefore recommended that the support team be systematic in their use of behavior monitoring data. The support team should review and analyze graphs at least once a week to determine whether Tier 2 interventions should be continued, modified, or terminated. Each decision, including those that result in no change to the plan, should be clearly communicated to all stakeholders. Such documentation is intended to demonstrate to all involved that assessment plays an important role and is a crucial part of Tier 2 service delivery.

Additional recommendations should be incorporated when DBR is to be applied as an intervention. Each is intended to increase the effectiveness of DBR, as well as its acceptability to teachers and students. First, the support team should establish clear criteria for any rewards that will be tied to the DBR intervention, such as the receipt of $80 \%$ of possible DBR points across the school day. Initial criteria should be at or slightly below baseline levels of behavior. This is meant to enhance the likelihood of the student being exposed to any rewarding stimuli (Cooper, Heron, \& Heward, 2007), thereby increasing his or her acceptability of the intervention and willingness to engage in DBR procedures. Second, rewards provided contingent upon the meeting of criteria should be small enough to be provided on a frequent basis. Reliance upon big or difficult-todeliver rewards can result in costly expenditure of school or teacher resources and students being reinforced too infrequently to elicit the desired effect in an effort to conserve these resources. Smaller rewards are less likely to strain already limited teacher time and school funds and are capable of being provided multiple times both within and across days. It is anticipated that enhancing the number of opportunities to encounter reinforcing stimuli will increase the immediacy and magnitude of behavior change.

When DBR data are used as the basis of communication, certain procedures should be incorporated to increase the potential for timely and effective correspondence. The student support team should work with each stakeholder, including educators and parents, to determine how shared DBR data will be used within their setting. It should be clear to educators and parents that DBR data are to serve as the basis for (a) positive feedback to the student regarding what he or she did well, and (b) conversations with the student regarding how he or she can behave in a more appropriate fashion under similar circumstances in the future. When possible, it should not be used as grounds for positive or negative punishment (e.g., time out, grounding, removal of privileges), as DBR is intended to be a positive strategy focused on adaptive behaviors that educators and parents would like the student to display with increasing frequency. 
The student support team should also identify the mode of communication through which DBR data will be transmitted, such as email, telephone, or school-home note, and confirm the acceptability, effectiveness, and reliability of communication modes with stakeholders. The team should work to remove barriers to DBR procedures (e.g., inability to access DBR data), such as home-based reinforcement, that are founded upon transmitted DBR data. This process is intended to increase the integrity with which DBR is applied and ensure all stakeholders are held accountable for their part of implementation.

When DBR is to be used as an intervention, the student support team should establish clear guidelines for treatment integrity assessment and intervention. Specific decisions should be made as to how integrity will be assessed, such as through the review of permanent product DBR data. The team also should decide how this information will be summarized and communicated, such as via verbal or graphic performance feedback (Sanetti, Luiselli, \& Handler, 2007). Finally, the team must establish criteria for treatment integrity intervention. For instance, it may be necessary to work with teachers to improve their integrity following three consecutive days wherein fewer than $80 \%$ of DBR intervention steps were implemented as intended.

\section{Conclusion}

Taken together, research clearly supports DBR as a foundation of Tier 2 service delivery for students engaging in disruptive but non-dangerous behavior, demonstrating its utility within multiple practices. Research has afforded support for the utility of DBR in assessment, indicating it may be used to monitor student progress (Chafouleas et al., 2010, 2012). Using single-case design methodologies, educators may interpret DBR data similarly to systematic direct observation data in determining whether student response to intervention supports the modification of the treatment plan to enhance the likelihood of positive results (Christ et al., 2009). DBR may be used as a highly efficient intervention, requiring minimal resources and teacher training for implementation. The tool may be more acceptable to teachers than other common treatment options, such as those that require frequent check-ins with students as part of an intermittent differential reinforcement procedure. DBR has proven flexible, with evidence supporting its use in isolation or in combination with other behavioral interventions to positively affect the behavior of a wide range of students who require Tier 2 support (Vannest et al., 2010). Data may be communicated across stakeholders within and across school and home settings for the purpose of enhancing buy-in and involvement, facilitating the coordination of service delivery, and increasing accountability (Chafouleas, 2011).

DBR is likely to prove acceptable to teachers who have grown accustomed to training across a range of tools, and who will likely welcome dedicating their valuable time and resources to learn and practice a single highly generalizable skill with a wide range of applications. It is also likely to be well-received by administrators and other 
student support staff (e.g., school psychologists, special educators), as incorporation of DBR into Tier 2 practices represents a feasible way to introduce evidence-based practice into the classroom. Through their capacity to assess student progress, influence student behavior, and serve as the foundation of stakeholder communication, DBR tools possess the potential to prevent or reduce behavioral difficulties experienced by many of the nation's youth.

\section{References}

Abikoff, H., Hechtman, L., Klein, R. G., Gallagher, R., Fleiss, K., Etcovitch, J., \& Pollack, S. (2004). Social functioning in children with ADHD treated with long-term methylphenidate and multimodal psychosocial treatment. Journal of the American Academy of Child and Adolescent Psychiatry, 43, 802-811. CrossRef GS Search

Baer, D. M., Wolf, M. M., \& Risley, T. R. (1968). Some current dimensions of applied behavior analysis. Journal of Applied Behavior Analysis, 1, 91-97. CrossRef GS Search

Briesch, A. M., Kilgus, S. P., Chafouleas, S. M., Riley-Tillman, T. C., \& Christ, T. J. (2013). The influence of alternative scale formats on the generalizability and of data obtained from Direct Behavior Rating Single-Item Scales (DBR-SIS). Assessment for Effective Intervention, 38, 127-133. CrossRef GS Search

Brooks, A., Todd, A. W., Tofflemoyer, S., \& Horner, R. H. (2003). Use of functional assessment and a self-management system to increase academic engagement and work completion. Journal of Positive Behavior Interventions, 5, 144-152. CrossRef $\underline{\text { GS Search }}$

Burke, M. D., Vannest, K., Davis, J., Davis, C., \& Parker, R. (2009). Reliability of frequent retrospective behavior ratings for elementary school students with EBD. Behavioral Disorders, 34, 212-222. GS Search

Campbell, A., \& Anderson, C. M. (2008). Enhancing effects of check-in/check-out with function-based support. Behavioral Disorders, 33, 233-245. GS Search

Campbell, A., \& Anderson, C. M. (2011). Check-in/check-out: A systematic evaluation and component analysis. Journal of Applied Behavior Analysis, 44, 315-326. CrossRef GS Search

Chafouleas, S. M. (2011). Direct Behavior Rating: A review of the issues and research in its development. Education and Treatment of Children, 34, 575-591. CrossRef GS Search 
Chafouleas, S. M., Briesch, A. M., Riley-Tillman, T. C., Christ, T. C., Black, A. C., \& Kilgus, S. P. (2010). An investigation of the generalizability and dependability of Direct Behavior Rating Single Item Scales (DBR-SIS) to measure academic engagement and disruptive behavior of middle school students. Journal of School Psychology, 48, 219-246. CrossRef GS Search

Chafouleas, S. M., Kilgus, S. P., Jaffery, R., Riley-Tillman, T. C., Welsh, M. E., \& Christ, T. J. (2013). Direct Behavior Rating as a school-based behavior screener for elementary and middle grades. Journal of School Psychology. CrossRef GS Search

Chafouleas, S. M., Riley-Tillman, T. C., \& Christ, T. J. (2009). Direct Behavior Rating (DBR): An emerging method for assessing social behavior within a tiered intervention system. Assessment for Effective Intervention, 34, 195-200. CrossRef GS Search

Chafouleas, S. M., Riley-Tillman, T. C., \& McDougal, J. (2002). Good, bad, or inbetween: How does the daily behavior report card rate? Psychology in the Schools, 39, 157-169. CrossRef GS Search

Chafouleas, S. M., Riley-Tillman, T. C., \& Sassu, K. A. (2006). Acceptability and reported use of daily behavior report cards among teachers. Journal of Positive Behavior Interventions, 8, 174-182. CrossRef GS Search

Chafouleas, S. M., Riley-Tillman, T. C., Sassu, K. A., LaFrance, M. J., \& Patwa, S. S. (2007). Daily behavior report cards: An investigation of the consistency of on-task data across raters and methods. Journal of Positive Behavior Interventions, 9, 30-37. CrossRef GS Search

Chafouleas, S. M., Riley-Tillman, T. C., \& Sugai, G. (2007). School-based behavioral assessment: Informing intervention and instruction. New York, NY: Guilford Press.

Chafouleas, S. M., Sanetti, L. M. H., Kilgus, S. P., \& Maggin, D. M. (2012). Evaluating sensitivity to behavioral change using Direct Behavior Rating Single-Item Scales. Exceptional Children, 78, 491-505. GS Search

Christ, T. J., Riley-Tillman, T. C., \& Chafouleas, S. M. (2009). Foundation for development and use of Direct Behavior Rating (DBR) to assess and evaluate student behavior. Assessment for Effective Intervention, 34, 201-213. CrossRef GS Search

Cooper, J. O., Heron, T. E., \& Heward, W. L. (2007). Applied behavior analysis (2nd ed.). Upper Saddle River, NJ: Pearson. 
Crone, D., Hawken, L., \& Horner, R. (2010). Responding to problem behavior in schools, Second Edition: The Behavior Education Program. The Guilford Practical Intervention in the Schools Series. New York, NY: Guilford Press.

Epstein, J. (1995). School/family/community partnerships: Caring for the children we share. Phi Delta Kappan, 76, 701-712. GS Search

Fabiano, G. A., Vujnovic, R., Naylor, J., Pariseau, M., \& Robins, M. L. (2009). Psychometric properties of Daily Behavior Report Cards used to provide progress monitoring for students with attention-deficit/hyperactivity disorder receiving special education. Assessment for Effective Intervention, 34, 231-241. CrossRef GS Search

Fabiano, G. A., Vujnovic, R. K., Pelham, W. E., Waschbusch, D. A., Massetti, G. M., Pariseau, M. E., . . Volker, M. (2010). Enhancing the effectiveness of special education programming for children with attention deficit hyperactivity disorder using a daily report card. School Psychology Review, 39, 219-239. GS Search

Filter, K. J., \& Horner, R. H. (2009). Function-based academic interventions for problem behavior. Education and Treatment of Children, 32, 1-19. CrossRef GS Search

Frafjord-Jacobson, K. L., Hanson, A. C., McLaughlin, T. F., Stansell, A., \& Howard, V. F. (2013). Daily report cards: A recommended intervention in schools. International Journal of Basics and Applied Sciences, 1, 461-472.

Gable, L. F. (2002). The efficacy of a school-home note intervention using internet communication for decreasing inappropriate classroom behaviors of secondary level students. Dissertation Abstracts International, 63, 496A. (UMI No. 3043147)

Gresham, F. M. (1989). Assessment of treatment integrity in school consultation and prereferral intervention. School Psychology Review, 18, 37-50. GS Search

Hintze, J. M., Christ, T. J., \& Methe, S. A. (2006). Curriculum-based assessment. Psychology in the Schools, 43, 45-56. CrossRef GS Search

Ingram, K., Lewis-Palmer, T., \& Sugai, G. (2005). Function-based intervention planning: Comparing the effectiveness of FBA function-based and non-function-based intervention plans. Journal of Positive Behavior Interventions, 7, 224-236. CrossRef GS Search

Jurbergs, N., Palcic, J., \& Kelley, M. L. (2007). School-home notes with and without response cost: Increasing attention and academic performance in low-income children with attention-deficit/hyperactivity disorder. School Psychology Quarterly, 22, 358-379. CrossRef GS Search 
Jurbergs, N., Palcic, J. L., \& Kelley, M. L. (2010). Daily behavior report cards with and without home-based consequences: Improving classroom behavior in low income, African American children with ADHD. Child and Family Behavior Therapy, 32, 177-195. CrossRef GS Search

Kilgus, S. P., Chafouleas, S. M., Riley-Tillman, T. C., \& Welsh, M. E. (2012). Diagnostic accuracy of Direct Behavior Rating Single Item Scales as a screener of elementary school students. School Psychology Quarterly, 27, 41-50. CrossRef

Kratochwill, T. R. (2007). Preparing psychologists for evidence-based school practice: Lessons learned and challenges ahead. American Psychologist, 62, 829-843. CrossRef GS Search

Kratochwill, T. R., Hoagwood, K. E., Kazak, A. E., Weisz, J. R., Hood, K., Vargas, L. A., \& Banez, G. A. (2012). Practice-based evidence for children and adolescents: Advancing the research agenda in schools. School Psychology Review, 41, 215235. GS Search

Lane, K. L., Bocian, K. M., MacMillan, D. L., \& Gresham, F. M. (2004). Treatment integrity: An essential - but often forgotten - component of school-based interventions. Preventing School Failure, 48, 36-43. CrossRef GS Search

LeBel, T. J., Chafouleas, S. M., Britner, P. A., \& Simonsen, B. (2013). Use of a daily report card in an intervention package involving home- school communication to reduce disruptive behavior in preschoolers. Journal of Positive Behavior Interventions, 15, 103-112. doi: 10.1177/1098300712440451 CrossRef GS Search

McCain, A. P., \& Kelley, M. L. (1993). Managing the classroom behavior of an ADHD preschooler: The efficacy of a school-home note intervention. Child and Family Behavior Therapy, 15, 33-44. CrossRef GS Search

McIntosh, K., Brown, J. A., \& Borgmeier, C. J. (2008). Validity of functional behavior assessment within a response to intervention framework evidence, recommended practice, and future directions. Assessment for Effective Intervention, 34, 6-14. CrossRef GS Search

Owens, J. S., Holdaway, A. S., Zoromski, A. K., Evans, S. W., Himawan, L. K., GirioHerrera, E., \& Murphy, C. E. (2012). Incremental benefits of a daily report card intervention over time for youth with disruptive behavior. Behavior Therapy, 43, 848-861. CrossRef GS Search 
Pang, I. W., \& Watkins, D. (2000). Towards a psychological model of teacher-parent communication in Hong Kong primary schools. Educational Studies, 26, 141-163. doi: 10.1080/713664272 CrossRef GS Search

Pelham, W. E., Hoza, B., Pillow, D. R., Gnagy, E. M., Kipp, H. L., Greiner, A. R., . . . Fitzpatrick, E. (2002). The effects of methylphenidate and expectancy on children with ADHD. Journal of Consulting and Clinical Psychology, 70, 320-325. CrossRef $\underline{\text { GS Search }}$

Power, T. J., Mautone, J. A., Soffer, S. L., Clarke, A. T., Marshall, S. A., Sharman, J., . . . Jawad, A. F. (2012). A family-school intervention for children with ADHD: Results of a randomized clinical trial. Journal of Consulting and Clinical Psychology, 80, 611-623. CrossRef GS Search

Riley-Tillman, T. C., Chafouleas, S. M., Briesch, A. M., \& Eckert, T. L. (2008). Daily behavior report cards and systematic direct observation: An investigation of the acceptability, reported training and use, and decision reliability among school psychologists. Journal of Behavioral Education, 17, 313-327. CrossRef GS Search

Riley-Tillman, T. C., Chafouleas, S. M., Christ, T. J., Briesch, A. M., \& LeBel, T. J. (2009). The impact of item wording and behavioral specificity on the accuracy of Direct Behavior Ratings (DBRs). School Psychology Quarterly, 24, 1-12. CrossRef GS Search

Sanetti, L. M. H., \& Kratochwill, T. R. (2009). Toward developing a science of treatment integrity: Introduction to the special series. School Psychology Review, 38, 445459. GS Search

Sanetti, L. M., Luiselli, J. K, \& Handler, M. W. (2007). Effect of verbal and graphic performance feedback on behavior support plan implementation in a public elementary school. Behavior Modification, 31, 454-465. CrossRef GS Search

Sanetti, L. M. H., \& Simonsen, B. (2011). Positive behavioral supports. In M. Bray \& T. Kehle (Eds.), Oxford handbook of school psychology (pp. 647-665). New York, NY: Oxford University Press.

Simonsen, B., Sugai, G., \& Negron, M. (2008). Schoolwide positive behavior supports: Primary systems and practices. Teaching Exceptional Children, 40(6), 32-40. GS Search

Solomon, B. G., Klein, S. A., \& Politylo B. C. (2012). The effect of performance feedback on teachers' treatment integrity: A meta-analysis of the single-case literature. School Psychology Review, 41, 160-175. GS Search 
Stage, S. A., Cheney, D., Lynass, L., Mielenz, C., \& Flower, A. (2012). Three validity studies of the daily progress report in relationship to the check, connect, and expect intervention. Journal of Positive Behavior Interventions, 14, 181-191. CrossRef GS Search

Vannest, K. J., Davis, J. L., Davis, C. R., Mason, B. A., \& Burke M. D. (2010). Effective intervention for behavior with a daily behavior report card: A meta-analysis. School Psychology Review, 39, 654-672. GS Search

Walberg, H. J. (1984). Families are partners in family productivity. Phi Delta Kappan, 65, 397-400. Retrivieved from ERIC database. (EJ293132)

Webber, J., Scheuermann, B., McCall, C., \& Coleman, M. (1993). Research on selfmonitoring as a behavior management technique in special education classrooms: A descriptive review. Remedial and Special Education, 14, 38-56. $\underline{\text { CrossRef }} \underline{\text { GS Search }}$

Williams, K. L., Noell, G. H., Jones, B. A., \& Gansle, K. A. (2012). Modifying students' classroom behaviors using an electronic daily behavior report card. Child and Family Behavior Therapy, 34, 269-289. CrossRef GS Search

Witt, J. C., Noell, G. H., LaFleur, L. H., \& Mortensen, B. P. (1997). Teacher use of interventions in general education settings: Measurement and analysis of the independent variable. Journal of Applied Behavior Analysis, 30, 693-696. CrossRef GS Search

\section{About the Author}

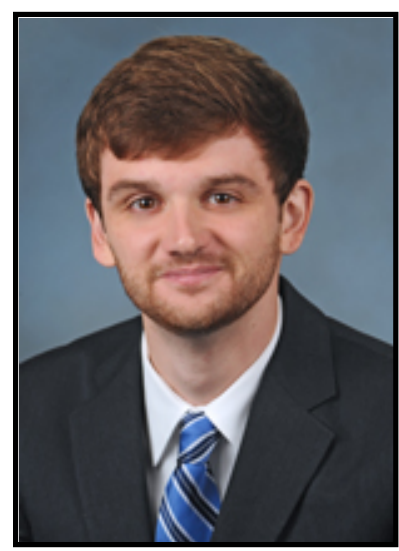

Dr. Stephen P. Kilgus is an Assistant Professor in the School Psychology Program in the Thomas Harriot College of Arts and Sciences at East Carolina University. He received his Ph.D. in school psychology from the University of Connecticut. His primary research interests include the development and evaluation of social behavior assessment tools and procedures, targeted behavior interventions and supports, and modern test theory. In 2012, he was awarded the Outstanding Dissertation Award by Division 16 of the American Psychological Association. He currently serves on the editorial board of multiple journals, including the Journal of School Psychology, School Psychology Quarterly, and Assessment for Effective Intervention. Email: kilguss@ecu.edu 